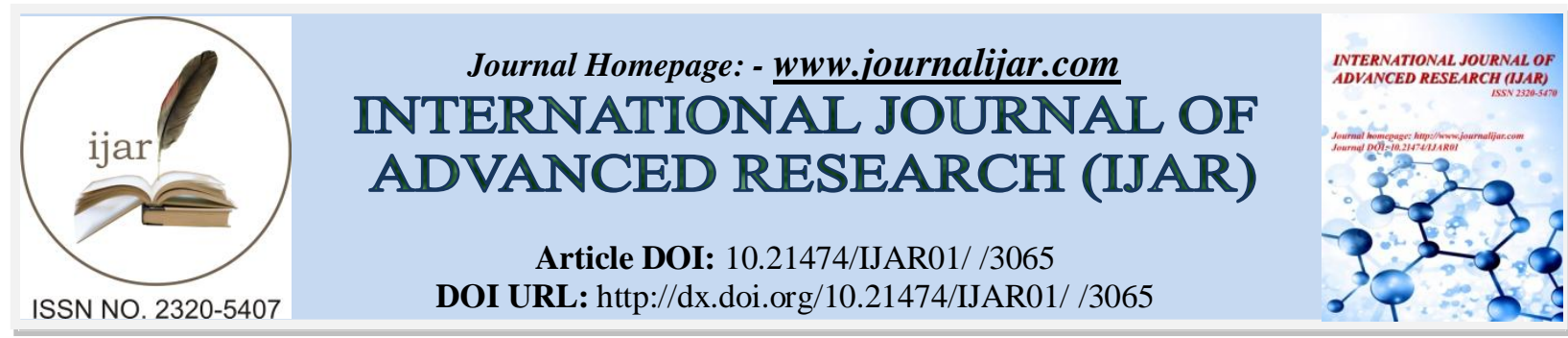

RESEARCH ARTICLE

\title{
SYSTEMATIC REVIEW OF EVIDENCE-BASED IN BENEFICIAL PREVENTING HYPOTHERMIA FOR ADULT TRAUMA PATIENTS IN ACCIDENT
}

\author{
Ahmad Abdullah Alghamdi, Hamdan Mujri Alaklabi, Khalid Mansi Alanazi and Mohammed Nasser \\ Makeen.
}

\section{Manuscript Info \\ Manuscript History}

Received: 03 December 2016

Final Accepted: 30 December 2016

Published: January 2017

\section{Abstract}

Accidental hypothermia increases mortality and morbidity in trauma patients. Various methods for insulating and wrapping hypothermic patients are used worldwide. Prevention and early correction of cold exposure is important because hypothermia is an independent predictor of increased morbidity and mortality in injured patients. Systematic review was conducted evidence based studies were searched in Pubmed, Embase, Cochrane central database, all to July, 2016. Every type of studies including revies, prospective studies and retrospective studies with prospective collected data were included. Qualities of included studies were assessed by a standardised scale previous reported for observational studies. It is difficult to determine whether admission hypothermia occurs because of prolonged patient exposure to ambient temperatures, heat loss from open body cavities, or because of aggressive fluid resuscitation with room temperature IV. Passive re-warming strategies and an effective first step on slowing the rate of deterioration, although these measures used in isolation are often insufficient to prevent hypothermia in severely injured patients.

Copy Right, IJAR, 2016,. All rights reserved.

\section{Introduction:-}

Major or severe trauma is the primary cause of death in up to $10 \%$ of all deaths worldwide. It is defined as having an Injury Severity Score (ISS) of 15 or greater ${ }^{(1)}$. Inadvertent injuries are the sixth leading cause of death and the fifth leading cause of severe disability internationally ${ }^{(1)}$. It is also the commonest cause of death for persons aged from 18-44 years ${ }^{(2)}$. In the developed countries, injury constitutes the leading causes of death among people aged 15-44 years and is increasingly a leading cause of death in the low-and middle-income countries, where death due to infection is also high ${ }^{(3)}$.

Trauma victims often suffer from hypothermia on arrival at hospital and, even when the hypothermia is moderate; it can be associated with a poorer prognosis and an increase in mortality rate ${ }^{(4-11)}$. Hypothermia is commonly found in injured victims and occurs in about 57\% trauma admission in Accident \& Emergency Department ${ }^{(16)}$. The definition of hypothermia is core temperature below $36^{\circ} \mathrm{C}$ in healthy subjects, or heat loss exceeds the heat production ability; but it is defined as temperature less than $36.5^{\circ} \mathrm{C}$ in injured victims ${ }^{(16)}$.

Early diagnosis of hypothermia is thus essential ${ }^{(4)}$. However, although the mechanisms of the deleterious effects of hypothermia are well known, its causes are not clear. Most published data on hypothermia victims are hospital registry data or data from retrospective studies ${ }^{(6-13)}$. 
A possible cause of hypothermia is the severity of the injury ${ }^{(4,6-11,14)}$. Both severe head injury and hypovolemic shock affect body temperature regulation. Although protecting the victim from the cold or warming them, whether passively or actively, might have a positive effect on body temperature, treatment such as vascular filling might impact negatively ${ }^{(15)}$.

Hypothermia is felt to be primarily a secondary event, that is, due to the injury itself. Animal models have shown a decrease in core body temperature correlating with blood pressure and not the level of resuscitation ${ }^{(18)}$. Human studies, while observational in nature, give a more mixed picture ${ }^{(19,20,21,22)}$. Physiology and injury severity seem to be the primary predictors of hypothermia, and these findings often correlate with the volume of resuscitation. In the studies to date, the majority of risk factors discussed appear to be secondary to the injury itself and the underlying changes to physiology. Factors commonly cited for hypothermia in trauma patients include extremes of age, environmental stresses, impaired neurological state or mobility, and subsequent care by health services ${ }^{(23)}$.

Hypothermia following traumatic injury, on the other hand, represents a failure of the body's compensatory mechanisms for thermoregulation. The body responds to heat loss by shivering, which increases oxygen consumption in skeletal muscles by $40 \%$ to $400 \%$. This high metabolic demand places some organs at risk of developing ischemia. By the time hypothermia develops, the energy reserves of the body are depleted and the system is showing signs of exhaustion. Hypothermia interferes with the clotting mechanisms of the blood by disrupting platelet function, slowing the chemical reactions that ultimately produce the protein strands necessary to build blood clots and by suppressing the immune system. A drop in body temperature of 1 degree Celsius results in a $6 \%$ to $7 \%$ decrease in cerebral blood flow, which could be dangerous for patients with traumatic brain injury ${ }^{(22,23)}$.

In trauma, several retrospective studies have found an association between higher death rate and an increasing degree of hypothermia, even accounting for differences in the severity of injury ${ }^{(7,11)}$. Jurkovich et al ${ }^{(7)}$ found that no trauma patient whose core temperature fell below $32{ }^{\circ} \mathrm{C}$ survived, and they regarded this as the critical temperature for survival. Hypothermia is recognized as one pillar of a "lethal triad" (hypothermia, acidosis and coagulopathy) of homeostatic failure that is believed to mark the limits of ongoing intervention, and necessitates an "abbreviated" laparotomy ${ }^{(26-30)}$.

Routine monitoring of temperature in severely injured patients is considered basic, but most techniques have not been validated in trauma patients. The most reliable core monitoring sites include the pulmonary artery, distal esophagus, nasopharynx, and tympanic membrane.

Swan and Ganz introduced the pulmonary artery catheter (PAC) in 1971 for measuring cardiac pressures. The PAC is the most accurate monitor and correlates to within $0.1{ }^{\circ} \mathrm{C}$ of core temperature ${ }^{(17,24)}$. However, its routine use is often precluded in trauma patients because it is technically cumbersome to insert and is associated with its own complications, including arrhythmias, perforation, and pericardial tamponade ${ }^{(41)}$. The PAC has not been shown to improve clinical outcomes and has fallen out of favor for routine use in most noncardiac intensive care situations ${ }^{(42)}$.

The oral temperature probe has existed since 1805 and has since gone through multiple iterations including the electronic clinical thermometer in $1954^{(43,44)}$. The oral probe is sensitive when placed correctly into the sublingual pouch next to the sublingual artery ${ }^{(45)}$. It can be altered by salivation, previous intake of hot or cold food, smoking, and rapid breathing ${ }^{(45)}$. Giuliano et al. ${ }^{(46)}$ evaluated the Welch-Allyn oral thermometer (model 670; Welch Allyn, Inc., San Diego, CA, USA) in 72 ICU patients and found a significantly lower variability in temperature values compared with the tympanic probe. They concluded that oral monitoring should be considered a first-choice device if a PAC is not warranted.

The tympanic infrared probe should be considered next since it is easily accessed from two identical sites and optimally located $3.5 \mathrm{~cm}$ from the hypothalamus. However, the temperature of the tympanic membrane, and not the brain, can be influenced by convective air currents generated during resuscitation efforts ${ }^{(47)}$. Tympanic temperatures should only be considered for monitoring when oral temperature is not feasible.

A noninvasive, disposable, medical thermometer, based on zero-heat-flux thermometry technology (3 M, St. Paul, MN, USA) is now available in North America. The probe's temperature is controlled to perfectly insulate the skin under the probe, which allows the warmer core tissue to warm the adjacent skin. In a study by Eshraghi et al. ${ }^{(48)}$, the 
zero-heat-flux thermometry technology matched the PAC within $0.2{ }^{\circ} \mathrm{C}$ during cardiac surgery. This device has not been studied in trauma and requires further evaluation.

Cork et al. ${ }^{(49)}$ evaluated the use of seven temperature monitors during anesthesia and compared their accuracy with tympanic measurements. Esophageal and nasopharyngeal temperatures were the most accurate while axillary temperatures were consistently $1.5-1.9^{\circ} \mathrm{C}$ below tympanic temperatures. Precision of measurements using the nasopharynx, esophagus, and bladder was found to be superior to those obtained in the axilla, forehead, or rectum.

Rectal, bladder, and axillary measurement techniques are each less accurate than the methods already discussed ${ }^{(50)}$. Rectal values have been shown to lag behind core temperature in cardiopulmonary bypass (CPB). As such, using the rectal temperature is considered an "intermediate" measuring technique because it is not representative of the true core temperature ${ }^{(50,51)}$. Bladder probes and axillary measurements are even less consistent, up to almost $1^{\circ} \mathrm{C}$ in variability ${ }^{(52)}$. Each technique can be disturbed by external temperatures, local blood flow, and incorrect placement ${ }^{(53)}$. Many measurements are considered insensitive and therefore the most practical technique with the best precision should be applied.

\section{We demonstrate here some of the physiological effects of hypothermia on humnan body systems. Cardiovascular effects:-}

Mild hypothermia $\left(<36^{\circ} \mathrm{C}\right)$ causes increased sympathetic tone, heart rate, blood pressure, and cardiac output while moderate hypothermia will depress cardiac activity ${ }^{(52,55)}$. At $34^{\circ} \mathrm{C}$, hypothermia impairs diastolic relaxation. By $28^{\circ} \mathrm{C}$, bradycardia develops with a prolonged PR interval, Osborne waves, and T-wave inversions followed by ventricular fibrillation at $25^{\circ} \mathrm{C}{ }^{(55)}$.

\section{Respiratory effects:-}

Mild hypothermia can increase the respiratory rate, causing a decrease in the partial pressure of carbon dioxide $\left(\mathrm{P}_{\mathrm{a}} \mathrm{CO}_{2}\right)$. At moderate levels, airway reflexes are reduced, predisposing a patient to aspiration. At $32{ }^{\circ} \mathrm{C}$, the medullary center becomes depressed, leading to a decrease in minute ventilation, increased secretions, and atelectasis ${ }^{(52,57)}$. Gas exchange is not affected, but there is an increase in pulmonary vascular resistance and ventilation-perfusion mismatch.

\section{Renal effects:-}

The initial increase in cardiac output, peripheral vascular resistance, and mean arterial pressure can lead to an in increase in renal blood flow and cold-induced diuresis ${ }^{(57)}$. With further heat loss the glomerular filtration rate decreases, reaching $50 \%$ of normal at approximately $30^{\circ} \mathrm{C}$. Urine output does not decrease until $20^{\circ} \mathrm{C}^{(57)}$.

\section{Hematological effects:-}

Clotting factor enzymes and platelets work optimally at $37^{\circ} \mathrm{C}$. Hypothermia impairs platelet function between 33 and $37^{\circ} \mathrm{C}$ and the activity of clotting factors and fibrinogen synthesis below $33^{\circ} \mathrm{C}{ }^{(58)}$. Rohrer and Natale investigated the effects of temperature on coagulation. Partial thromboplastin time levels increased from $36.0 \mathrm{~s}$ at $37^{\circ} \mathrm{C}$ to $39.4,46.1$, and $57.2 \mathrm{~s}$ at $34^{\circ} \mathrm{C}, 31^{\circ} \mathrm{C}$, and $28^{\circ} \mathrm{C}$, respectively ${ }^{(59)}$. Temperatures below $33{ }^{\circ} \mathrm{C}$ also inhibit thrombin, glycoprotein Ib-IX complex, platelet aggregation, and thromboxane B2 production. One study investigated the reversibility of these effects in whole blood flow cytometric analysis and the complications were shown to resolve with rewarming back to $37^{\circ} \mathrm{C}^{(60)}$.

\section{Hypothermia and trauma-induced coagulopathy:-}

Trauma-induced coagulopathy (TIC) is present in one-quarter of all severely injured patients and carries a $46 \%$ mortality rate ${ }^{(61)}$. Several important processes, including the release of heparanoids from the endothelial glycocalyx, protein $\mathrm{C}$ activation, tissue plasminogen activator, hyperfibrinolysis, and platelet dysfunction, have been implicated

${ }^{(61)}$. The concept of early TIC is a new model that has not yet been entirely elucidated. However, several recent trials have identified a prolonged prothrombin time and therefore coagulopathy in the early time period after initial trauma in $25 \%$ of patients ${ }^{(62)}$. There are seven mechanisms involved in its development: shock, tissue trauma, inflammation, acidemia, hemodilution, massive transfusion, and hypothermia ${ }^{(61)}$. Bukur et al. ${ }^{(63)}$ retrospectively reviewed 21,023 trauma patients and found $44.6 \%$ of prehospital patients had significant hypothermia, which can exacerbate all other mechanisms. 
While shock is thought to be the primary driver of coagulopathy, tissue injury is still required for its initiation. Hypoperfusion causes tissues to become hypoxic and leads to lactic acidosis, which along with hypothermia decreases the activity of the coagulation cascade and increases fibrinolysis ${ }^{(64)}$. Sustained hypoperfusion increases thrombomodulin, which can increase thrombomodulin-bound thrombin that activates protein $\mathrm{C}$, a systemic anticoagulant ${ }^{(64,65)}$.

\section{Objective:-}

Physicians commonly ignore hypothermiaand itrelation with mortality in trauma patients, in general due to its prevalence and belief that it is secondary to the injury itself (secondary hypothermia). Over the past several decades, hypothermia in trauma has been studied concerning its effects on mortality; however, very little has been done to identify the beneficial effect of preventing hypothermia among adult traumatic patients, and the different procedures and strategies, Thus this study aimed to systemically review the evidence of prevention hypothermia in traumatic patients and its beneficial effect on their health.

\section{Methodology:-}

Study design:-

Systematic review of literature.

\section{Search strategy:-}

Systematic review was conducted evidence based studies were searched in we searched three electronic databases (Pubmed, EMBASE and ISI Web of Science) using the following search strategy: (hypothermia OR temperature) AND (tauma OR accident OR injury, Search was to July, 2016. Every type of studies including revies, prospective studies and retrospective studies with prospective collected data were included. Qualities of included studies were assessed by a standardised scale previous reported for observational studies. The effects of individual studies were combined with the study quality score using a previous reported model of best-evidence synthesis. The hazard ratios of strong evidence predictors were combined only by high quality studies. the inclusion and exclusion criteria are identified after a systematic research of six electronic databases. Among these articles, four of them are randomized controlled trials while the remaining one is quasi-experimental design with prospective randomized assignment. The quality of these identified articles is evaluated with the methodology checklist for randomized controlled trials which is developed by Scottish Intercollegiate Guideline Network (SIGN). All studies of medium and high quality would be considered as sufficient evidence to support the proposed innovation in preventing hypothermia for trauma patients in Accident.

\section{Results:-}

Trauma patients are at great risk of accidental hypothermia (body temperature $[\mathrm{BT}]<36$ degrees C). Hypothermia influences the functioning of all organ systems and can lead to pathological changes, which in turn additionally complicate the trauma. Furthermore, hypothermia can, e.g., by influencing blood coagulation (reduction of thrombocyte aggregation, increased fibrinolysis) have a markedly unfavourable impact upon the in-hospital surgical treatment of the trauma patient.If the patient begins to shiver, it means that hypothermia is beginning to occur. Shivering increases oxygen consumption by the muscle cells by as much as 400 percent.

Therefore, the goal of prehospital care is to avoid the onset of shivering. Basic passive heating measures such as covering the patient and turning on the patient compartment heater until it is uncomfortably warm can slow down the loss rate.

\section{Different risk factor associated with hypothermia in traumatic patients:-}

The prevalence of hypothermia in trauma victims on arrival at hospital was high (14\%) and was associated with several risk factors as it was stated in Danzl et al ${ }^{(13)}$. The most significant factor was the severity of the injury as given by the RTS. The relationship between hypothermia and severity of injury is known ${ }^{(13)}$. Different study by Luna et al showed that not only blood loss and spine or head injury impair body temperature regulation, even if not always immediately. Intubation was also a significant risk factor. It was no doubt a sign of the severity of the injury ${ }^{(11)}$. Head injury, RTS, and intubation were all three, severity criteria independently associated with hypothermia ${ }^{(11)}$.

However some other studies have showed that the infusion fluid temperature was noticed, for the first time, to be a significant risk factor for the onset of hypothermia ${ }^{(33,34)}$. The temperature of the fluid infused on resuscitation of 
$75 \%$ of the patients with hypothermia on arrival at hospital was below $21^{\circ} \mathrm{C}$ and close to air temperature. Infusion temperature was a more important risk factor than infusion volume, maybe partly because of the small infusion volumes used. Another significant factor was mobile unit temperature. In order to minimize hypothermia in trauma victims, therefore some studies have recommend that infusion fluid temperature be controlled, that small infusion volumes be used for resuscitation, that the mobile unit be heated, and that trauma victims preferably remain clothed $(33,34,35)$

We identified observational study ${ }^{(35)}$ carried out by the mobile EMS of eight French hospitals between 1 January 2004 and 10 November 2007, that included Body temperature measurements on arrival at hospital were available for 448 patients. The distribution is shown in Figure 1 . Hypothermia (body temperature $<35^{\circ} \mathrm{C}$ ) was present in 64 of these 448 patients $(14 \%)$. and therefore they for patients safety they recommended that Optimal patient management could contribute to limit heat loss or even to increase the patient's temperature when required. Undressing patients should be avoided. Mobile unit temperature and fluid infusion temperature were independently associated with hypothermia. They should be routinely measured. Adapted tools are available.

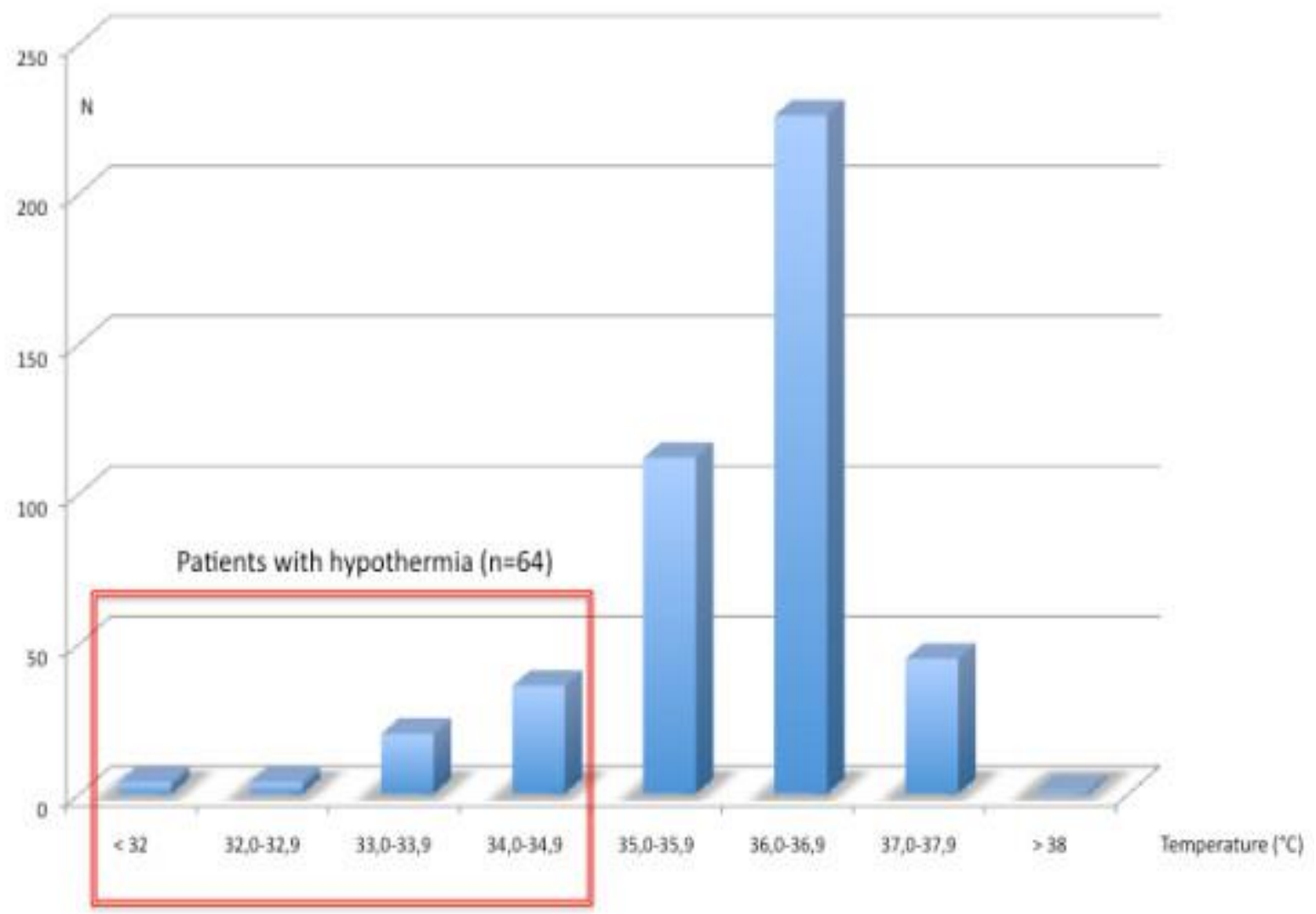

Figure 1:- Temperature distribution in the 448 trauma victims on arrival at hospital ${ }^{(35)}$.

Hypothermia Prevention among adults traumatic patients:-

We identified five ${ }^{(36,37,38,39,40)}$ clinical randomized trials, the sample size of two studies were 100 participants ${ }^{(37)}$ and 298patients ${ }^{(36)}$. The other two studies had sample sizes of 30 patients $^{(38)}$ and 48 paitents $^{(40)}$. One study was within subject design and had sample sizes of $10^{(39)}$.three out of thosestudies included patients which were all minor to medium level trauma with abdominal trauma, fractures, contusion, hematoma and injury severity scored ${ }^{(36,37,38)}$. One of the studies ${ }^{(39)}$ recruited patients who suffer burn accidents with total burn surface area greater than $20 \%$ (ranged from $20 \%$ to $87 \%$ ). The other article was patients with blunt trauma who were under cold stress ${ }^{(40)}$. The age of the subjects were from 20 to 78 with mean age of 38-58 in the four articles except one of them failed to provide the age of subjects ${ }^{(36)}$. 
Two studies ${ }^{(37,38)}$ of the previous mentioned investigated the effect of carbon fiber heating blanket with temperature set to $42^{\circ} \mathrm{C}$ when compared to the control group which was same carbon fiber heating blanket without switching on the electricity and the duration of warming devices applied was about one hour in bothstudies ${ }^{(37,38)}$. The device was portable and easy to implement which contained batteries of $0.5 \mathrm{~kg}$ and could last for $30-40$ minutes.

One of the five articles ${ }^{(36)}$ investigated and compared the thermal efficiency among reflective blanket, prewarmed cotton blanket and forced-air inflatable blanket without specifying the control groups ${ }^{(36)}$. Another one article investigated the effect of using large chemical heat pad 16 applied to upper torso and passive warming blankets when compared to passive warming blankets only as control group,the mean of warming duration was $35+/-26$ minutes ${ }^{(40)}$. The remaining one compared the effect among temperature regulating water circulating mattress + infusion heater, temperature regulating air circulating mattress + infusion heater, and conventional heating which were radiator ceilings, bed warmers and infusion heater ${ }^{(39)}$.

Three articles used aural probe which was gently placed in aural canal and occluded with cotton as measuring tool for continuous core temperature measurement (Kober et al, 2001; Scheck et al, 2004; Ludgren et al, 2011) ${ }^{(37,38,40)}$. In Cohen et al $(2002)^{(36)}$, electronic 17 thermometer either orally or rectally were used as measuring tool for core temperature measurement if urinary catheter thermistor was not feasible. In the article (Kjellman et al, 2011) ${ }^{(39)}$, an indwelling (bladder) thermistor was used as a tool to measure core temperature.

Our review included a cohort study ${ }^{(41)}$ that involved 2848 Adults traumatic patients; $18 \%$ were hypothermic (temperature < 36 degrees $\mathrm{C}$ ). Hypothermia was significantly $(\mathrm{P}<.05)$ correlated with admission Glasgow Coma Scale (GCS), tachycardia, hypotension, lower hematocrit, and acidosis. Hypothermic patients had a significantly higher blood product and factor VIIa requirement. Hypothermia was an independent predictor of operative management of injuries, and overall mortality $(\mathrm{P}<.05)$. This study stated that Combat trauma patients have a high percentage of penetrating injuries with variable evacuation times. Hypothermia was a pre-hospital physiologic marker, and independent contributor to overall mortality. Concluded that the prevention of hypothermia could reduce resource utilization and improve survival in the combat setting ${ }^{(41)}$.

In concern with the prevention of hypothermia in adult patients we identified a prospective, randomized study ${ }^{(25)}$. Mentioned study involved 61 physical status of adults undergoing major surgery and general anesthesia with isoflurane which consider a type of intention traumatic procedures. Patients were divided into two groups the temperatures measured showed, Lowest and final intraoperative distal esophageal temperatures were higher $(\mathrm{p}<$ 0.05) in Group 1 (mean +/- SEM: $35.8+/$ - 0.1 degrees $C$ and $36.6+/-0.1$ degrees C) versus Group $2(35.4+/-0.1$ degrees $\mathrm{C}$ and $36.1+/-0.1$ degrees $\mathrm{C}$, respectively). Compared with Group 1, more Group 2 patients were hypothermic at the end of anesthesia (10 of 26 patients, or $38.5 \%$ vs. 4 of 30 patients, or $13 \%$; p < 0.05 ). And the results showed After 30 minutes in the recovery room, there were no differences in temperature between groups (36.7 +/- 0.1 degrees $C$ and $36.5+/-0.1$ degrees $C$ in Groups 1 and 2, respectively). Intraoperative cessation of convective warming because of core temperature greater than 37 degrees $\mathrm{C}$ was required in $33 \%$ of Group 1 patients (vs. $11.5 \%$ in Group 2; p = 0.052). All patients received convective warming. Group 1 patients received warmed fluids (setpoint 42 degrees C). Group 2 patients received room temperature fluids (approximately 21 degrees C). Therefore this study showed the combination of convective and fluid warming was associated with a decreased likelihood of patients leaving the operating room hypothermic. However, average final temperatures were greater than 36 degrees $\mathrm{C}$ in both groups, and intergroup differences were small. Care must be taken to avoid overheating the patient when both warming modalities are employed together ${ }^{(25)}$.

Another retrospective trail ${ }^{(8)}$ was identified which was analysis of data total of 2182 patients from the Queensland Trauma Registry, Australia, and included all patients admitted to hospital during 2003 and 2004 with an injury severity score (ISS)>15. Demographic, injury, environmental, care and clinical status factors were considered. 124 (5.7\%) of patients had hypothermia on admission to the definitive care hospital, while a further 156 (7.1\%) developed hypothermia during hospitalisation. Factors associated with hypothermia on admission included winter, direct admission to a definitive care hospital, an ISS $>$ or $=40$, a Glasgow Coma Scale of 3 or ventilated and sedated, and hypotension on admission. Hypothermia on admission to the definitive care hospital was an independent predictor of mortality. Hypothermia during definitive care hospitalisation was independently associated with mortality (OR=2.52; 95\% CI 1.52-4.17), intensive care admission ( $\mathrm{OR}=1.73$; 95\% CI 1.20-2.93) and hospital length of stay (IRR=1.18; 95\% CI 1.02-1.36). This study has stated that Trauma patients in a predominantly sub-tropical 
climate are at risk of accidental and endogenous hypothermia, with associated higher mortality and care requirements, the study highlighted that prevention of hypothermia is important for all severely injured patients ${ }^{(8)}$.

The last study ${ }^{(31)}$ which was included to our study was aimed determined the efficacy of three hypothermia prevention strategies: the ChillBuster warming blanket, ChillBuster with a reflective blanket, and two wool blankets. A quasi-experimental design was used to compare changes in core temperature. Following resuscitation from hypovolemic shock, 20 swine were assigned to one of the three interventions, placed in an environmental chamber set to reproduce in-flight conditions onboard a military cargo aircraft (50 degrees F/airspeed $0.2 \mathrm{~m} / \mathrm{s}$ ), and monitored for 6 hours. A repeated measures analysis of variance and least-squared difference post hoc were performed. The ChillBuster/reflective blanket group was significantly warmer than the ChillBuster only group and the wool blanket group ( $\mathrm{p}$ < 0.01). After 6 hours of cold exposure, the ChillBuster/reflective blanket group remained warm while the ChillBuster only and wool blanket groups developed mild hypothermia. Combined use of a warming blanket and reflective blanket was effective in preventing hypothermia over 6 hours and is feasible in a deployed military environment ${ }^{(7,39,)}$.

Important differences in rewarming techniques:-

Because patients remain threatened for as long as they're hypothermic, rapid and efficient rewarming is crucial. A variety of methods are used to gain normothermia in the trauma patient. They are generally divided into three groups: passive external rewarming, active external rewarming, and active internal rewarming. The patient's temperature and condition, and your hospital's resources, govern which maneuver to use. For more severe hypothermia, more aggressive rewarming techniques are warranted ${ }^{(39)}$.

Passive external rewarming is used when there's minimal heat loss. Heat is regained by means of the body's intrinsic ability to generate heat. Examples of passive external rewarming include bringing the patient indoors and providing him with warm blankets and hats.

Active external rewarming is used when there's moderate heat loss. Radiant rewarmers, fluid-filled blankets, and convection warming units are among the devices used. Monitor the patient's core temperature closely, as he can continue to lose heat or fail to rewarm despite active external devices if he is significantly cold at the onset of therapy $^{(66)}$.

Fluid-circulating blankets make contact with only $20 \%-30 \%$ of the body surface area, which can hamper their efficiency. They should always be placed on top of the patient to prevent tissue necrosis and further heat loss ${ }^{(66)}$.

Convection blankets circulate air at $109.4^{\circ} \mathrm{F}\left(43^{\circ} \mathrm{C}\right)$ at a flow rate of 400 cubic feet per minute. But air has very little thermal energy, which means these blankets are able to prevent further heat loss but are slow in active rewarming. They're best augmented by covering the patient's head ${ }^{(66)}$. Active internal rewarming is indicated for patients with moderate to severe hypothermia. ${ }^{1}$ The use of entrained warmed gas into the endotracheal tube is the least invasive internal maneuver. Oxygen can be warmed to $107.6^{\circ}-114.8^{\circ} \mathrm{F}\left(42^{\circ}-46^{\circ} \mathrm{C}\right)$ without damage to the pulmonary parenchyma ${ }^{(66)}$.

Another method of active internal rewarming is the use of rapid infuser fluid warmers, which have been the mainstay of resuscitation of hypothermic trauma patients. Fluids and blood can be warmed to $104^{\circ} \mathrm{F}\left(40^{\circ} \mathrm{C}\right)$ and infused at a rate of about one liter per minute. These devices maintain a steady state with rate and temperature regulation. Unlike rapid infuser fluid warmers, standard fluid warming devices have been found to be ineffective in keeping fluid temperatures warm, as they pass through coils of tubing at a rate of $125 \mathrm{ml} /$ hour or less $^{(66)}$.

Irrigation of body cavities with warmed fluids is another method of active internal rewarming. The amount of heat transfer depends on the difference between the inlet and outlet of water temperatures. The pleural cavity and peritoneal cavity are equally effective for rewarming. These cavities first need to be checked carefully to make sure they're intact. Diagnostic studies should be performed to rule out pneumohemothorax or diaphragmatic injury before beginning fluid administration. This technique can increase body temperature $1^{\circ}-2^{\circ} \mathrm{C}$ per hour ${ }^{(66)}$.

Cardiopulmonary bypass (CPB), which diverts the flow of blood via a pump oxygenator and heat exchanger to avoid both the heart and lungs, is considered to be the "gold standard" therapy for a hypothermic patient with cardiovascular instability. $\mathrm{CPB}$ is usually reserved for those with a body temperature lower than $82.4^{\circ} \mathrm{F}\left(28^{\circ} \mathrm{C}\right)$ and 
can increase body temperature at a rate of $10^{\circ}-12^{\circ} \mathrm{C}$ per hour. In addition to rewarming, $\mathrm{CPB}$ can help oxygenate and perfuse organs despite ventricular fibrillation or asystole ${ }^{(5,39,66)}$.

\section{Conclusion:-}

Normal human body temperature is 35.6-37.8 degrees $C$ with hypothermia being defined as a core temperature $<35$ degrees C.5 In many of our reviewd study, it was found that almost half of EMS-transported trauma patients had a temperature $<36$ degrees $\mathrm{C}$ on arrival to the ED. 6 Important to note is that there was no association between season of the year and frequency of hypothermia. At highest risk were those patients older than 65 and those who had been entrapped.6 In addition, hypothermia in trauma has been associated with a significantly increased mortality compared to patients with the same body temperature from environmental exposure alone. Most of these studies trauma victims, a core temperature $<32$ degrees $\mathrm{C}$ was associated with $100 \%$ mortality independent of the presence of shock, injury severity or volume of fluid resuscitation. Because hypothermia in a trauma patient predicts such a poor outcome, the traditional classification system of hypothermia has been revised for use in this vulnerable patient population. It is difficult to determine whether admission hypothermia occurs because of prolonged patient exposure to ambient temperatures, heat loss from open body cavities, or because of aggressive fluid resuscitation with room temperature IV. Medics often disrobe trauma patients early in the assessment, thereby enhancing radiant heat loss that occurs when there is a significant temperature gradient between the environment and the patient's skin. Reversing hypothermia is an effective strategy for improving outcome. However, once hypothermia develops, it is not resolved quickly or easily.

One of the easiest ways to begin combating the harmful effects of hypothermia is to undertake passive warming strategies such as removing the trauma patient from the cold environment as quickly as possible, raising the temperature in the back of the ambulance, and covering the patient with a blanket. Although passive interventions are effective for mild hypothermia if the patient's thermoregulatory mechanisms are intact, this strategy will still allow trauma patients to cool.

\section{References:-}

1. Soreide K. Epidemiology of major trauma. Br J Surg. 2009;96:697-8. doi: 10.1002/bjs.6643.

2. McLarty, C.D. (2012). Hypothermia in the Trauma Patient. How Vital Is This Sign?

3. Krug EG, Sharma GK, Lozano R. The global burden of injuries. Am J Public Health 2000;90:523-6.

4. Waibel BH, Durham CA, Newell MA, Schlitzkus LL, Sagraves SG, Rotondo MF. Impact of hypothermia in the rural, pediatric trauma patient. Pediatr Crit Care Med. 2010;11:199-204. doi: 10.1097/PCC.0b013e3181b80500.

5. Waibel BH, Schlitzkus LL, Newell MA, Durham CA, Sagraves SG, Rotondo MF. Impact of hypothermia (below 36 degrees $C$ ) in the rural trauma patient. J Am Coll Surg. 2009;209:580-588. doi: 10.1016/j.jamcollsurg.2009.07.021.

6. Beilman GJ, Blondet JJ, Nelson TR, Nathens AB, Moore FA, Rhee P, Puyana JC, Moore EE, Cohn SM. Early hypothermia in severely injured trauma patients is a significant risk factor for multiple organ dysfunction syndrome but not mortality. Ann Surg. 2009;249:845-850. doi: 10.1097/SLA.0b013e3181a41f6f.

7. Jurkovich GJ, Greiser WB, Luterman A, Curreri PW. Hypothermia in trauma victims: an ominous predictor of survival. J Trauma. 1987;27:1019-1024. doi: 10.1097/00005373-198709000-00011.

8. Aitken LM, Hendrikz JK, Dulhunty JM, Rudd MJ. Hypothermia and associated outcomes in seriously injured trauma patients in a predominantly sub-tropical climate. Resuscitation. 2009;80:217-223. doi: 10.1016/j.resuscitation.2008.10.021.

9. Shafi S, Elliott AC, Gentilello L. Is hypothermia simply a marker of shock and injury severity or an independent risk factor for mortality in trauma patients? Analysis of a large national trauma registry. J Trauma. 2005;59:1081-1085.

10. Wang HE, Callaway CW, Peitzman AB, Tisherman SA. Admission hypothermia and outcome after major trauma. Crit Care Med. 2005;33:1296-1301. doi: 10.1097/01.CCM.0000165965.31895.80.

11. Luna GK, Maier RV, Pavlin EG, Anardi D, Copass MK, Oreskovich MR. Incidence and effect of hypothermia in seriously injured patients. J Trauma. 1987;27:1014-1018. doi: 10.1097/00005373-198709000-00010.

12. Martin RS, Kilgo PD, Miller PR, Hoth JJ, Meredith JW, Chang MC. Injury-associated hypothermia: an analysis of the 2004 National Trauma Data Bank. Shock. 2005;24:114-118. doi: 10.1097/01.shk.0000169726.25189.b1.

13. Danzl DF, Pozos RS, Auerbach PS, Glazer S, Goetz W, Johnson E, Jui J, Lilja P, Marx JA, Miller J. et al. Multicenter hypothermia survey. Ann Emerg Med. 1987;16:1042-1055. doi: 10.1016/S0196-0644(87)80757-6. 
14. Mitra B, Al Jubair J, Cameron PA, Gabbe BJ. Tram-related trauma in Melbourne, Victoria. Emerg Med Australas. 2010;22:337-342. doi: 10.1111/j.1742-6723.2010.01309.x.

15. Gregory JS, Flancbaum L, Townsend MC, Cloutier CT, Jonasson O. Incidence and timing of hypothermia in trauma patients undergoing operations. J Trauma. 1991;31:795-798; discussion 798-800. doi: 10.1097/00005373-199106000-00009.

16. Stewart, S.K. (2003). Hypothermia in Trauma. North Central Texas Trauma Regional Advisory Council. Vol 5, No. 2

17. Milewski A, Ferguson KL, Terndrup TE. Comparison of pulmonary artery, rectal, and tympanic membrane temperatures in adult intensive care unit patients. Clin Pediatr. 1991;30(4 Suppl):13-6. doi: $10.1177 / 000992289103000405$.

18. Bergstein JM, Slakey DP, Wallace JR, Gottlieb M. Traumatic hypothermia is related to hypotension, not resuscitation. Ann Emerg Med. 1996;16:39-42. doi: 10.1016/S0196-0644(96)70294-9.

19. Gregory JS, Flancbaum L, Townsend MC, Cloutier CT, Jonasson O. Incidence and timing of hypothermia in trauma patients undergoing operations. J Trauma. 1991;16:795-8. doi: 10.1097/00005373-199106000-00009.

20. Bernabei AF, Levison MA, Bender JS. The effects of hypothermia and injury severity on blood loss during trauma laparotomy. J Trauma. 1992;16:835-839. doi: 10.1097/00005373-199212000-00007.

21. Ireland S, Endacott R, Cameron P, Fitzgerald M, Paul E. The incidence and significance of accidental hypothermia in major trauma--a prospective observational study. Resuscitation. 2011;16:300-306. doi: 10.1016/j.resuscitation.2010.10.016.

22. Waibel BH, Newell MA, Durham CA, Barrett MR, Schlitzkus LL, Rotondo MF. Predictors of hypothermia in trauma patients. Crit Care Med. 2010;16(12 Suppl):208.

23. Kirkpatrick AW, Chun R, Brown R, Simons RK. Hypothermia and the trauma patient. Can J Surg.1999;16:333-343. [

24. Nierman DM. Core temperature measurement in the intensive care unit. Crit Care Med. 1991;19:818-23. doi: 10.1097/00003246-199106000-00015.

25. Smith CE, Desai R, Glorioso V, Cooper A, Pinchak AC, Hagen KF. Preventing hypothermia: convective and intravenous fluid warming versus convective warming alone. J Clin Anesth. 1998 Aug;10(5):380-5.

26. Ferrara A, MacArthur JD, Wright HK, Modlin IM, McMillen MA. Hypothermia and acidosis worsen coagulation in the patient requiring massive transfusion. Am J Surg 1990;160:515-8.

27. Stone H, Strom P, Mullins R. Management of the major coagulopathy with onset during laparotomy. Ann Surg 1983;197:532-5.

28. Burch JM, Ortiz VB, Richardson J, Martin RR, Mattox KL, Jordan GL. Abbreviated laparotomy and planned reoperation for critically ill patients. Ann Surg 1992;215:476-83.

29. Hirshberg A, Walden R. Damage control for abdominal trauma. Surg Clin North Am 1997;77:813-9.

30. Mattox KL. Introduction, background, and future projections of surgery. Surg Clin North Am 1997;77:753-9.

31. Schmelz JO1, Bridges EJ, Wallace CM, Sanders SF, Shaw T, Kester N, Bauer S, Sylvester JC. Comparison of three strategies for preventing hypothermia in critically injured casualties during aeromedical evacuation. Mil Med. 2007 Mar;172(3):322-6.

32. Arthurs Z1, Cuadrado D, Beekley A, Grathwohl K, Perkins J, Rush R, Sebesta J. The impact of hypothermia on trauma care at the 31st combat support hospital. Am J Surg. 2006 May;191(5):610-4.

33. Gregory JS, Flancbaum L, Townsend MC, Cloutier CT, Jonasson O. Incidence and timing of hypothermia in trauma patients undergoing operations. J Trauma. 1991;31:795-798; discussion 798-800. doi: 10.1097/00005373-199106000-00009.

34. Farkash U, Lynn M, Scope A, Maor R, Turchin N, Sverdlik B, Eldad A. Does prehospital fluid administration impact core body temperature and coagulation functions in combat casualties? Injury.2002;33:103-110. doi: 10.1016/S0020-1383(01)00149-8.

35. Frédéric Lapostolle, Jean Luc Sebbah, James Couvreur, François Xavier Koch, Dominique Savary, Karim Tazarourte, Gerald Egman, Lynda Mzabi, Michel Galinski, and Frédéric Adnet. Risk factors for onset of hypothermia in trauma victims: The HypoTraum study. Crit Care. 2012; 16(4): R142.doi: 10.1186/cc11449.

36. Cohen, S., Hayes, J. S., Tordella, T. \& Puente, I (2002). Thermal Efficiency of Prewarmed Cotton, Reflective, and Forced-Warm Air Inflatable Blankets in Trauma Patients. International Journal of Trauma Nursing. 8(1) 4-8.

37. Kober, A., Scheck, T., Fulesdi, B., Lieba, F., Vlach, W., Friedman, A. \& Sessler, D.I. (2001). Effectiveness of Resistive Heating Compared with Passive Warming in Treating Hypothermia Associated With Minor Trauma: A Randomized Trial. Mayo Clinic Proceedings. 76(4) 369-375. 
38. Scheck, T., Kober, A., Bertalanffy,P., Aram, L., Andel, H., Molnar, C. \& Hoerauf, K. (2004). Active warming of critically ill trauma patients during intrahospital transfer: A prospective, randomized trial. Wien Klin Wochenschr. 116(3): 94-97.

39. Kjellman, B.M., Fredrikson, M., Glad-Mattsson, G., Sjoberg, F. \& Huss, F.R. (2011). Comparing ambient, airconvection, and fluid-convection heating techniques in treating hypothermic burn patients, a clinical RCT. Annals of surgical Innovation and Research. 5:4,1-8.

40. Lundgren, P., Henriksson, O., Naredi, P. \& Bjornstig, U. (2011). The effect of active warming in prehospital trauma care during road and air ambulance transportation-a clinical randomized trial. Scandinavian Journal of Trauma, Resuscitation \& Emergency Medicine. 19(59): 1-7.

41. Elliott CG, Zimmerman GA, Clemmer TP. Complications of pulmonary artery catheterization in the care of critically ill patients. A prospective study. Chest. 1979;76:647-52. doi: 10.1378/chest.76.6.647.

42. Bender JS, Smith-Meek MA, Jones CE. Routine pulmonary artery catheterization does not reduce morbidity and mortality of elective vascular surgery: results of a prospective, randomized trial. Ann Surg.1997;226:22936. doi: 10.1097/00000658-199709000-00002.

43. Jefferies S, Weatherall J, Young P. A systematic review of the accuracy of peripheral thermometry in estimating core temperatures among febrile critically ill patients. Crit Care Resusc. 2011;13:194-9.

44. Barringer LB, Evans CW, Ingram LL, Tisdale PP, Watson SP, Janken JK. Agreement between temporal artery, oral, and axillary temperature measurements in the perioperative period. J Perianesth Nurs.2011;26:143-50. doi: 10.1016/j.jopan.2011.03.010.

45. Erickson R. Oral temperature differences in relation to thermometer and technique. Nurs Res.1980;29:157-64. doi: 10.1097/00006199-198005000-00004.

46. Giuliano KK, Scott SS, Elliot S, Giuliano AJ. Temperature measurement in critically ill orally intubated adults: a comparison of pulmonary artery core, tympanic, and oral methods. Crit Care Med. 1999;27:2188-93. doi: 10.1097/00003246-199910000-00020.

47. Patel N, Smith CE, Pinchak AC, Hagen JF. Comparison of esophageal, tympanic, and forehead skin temperatures in adult patients. J Clin Anesth. 1996;8:462-8. doi: 10.1016/0952-8180(96)00103-1.

48. Eshraghi Y, Nasr V, Parra-Sanchez I, Van Duren A, Botham M, Santoscoy T. An evaluation of a zero-heat-flux cutaneous thermometer in cardiac surgical patients. Anesth Analg. 2014;119:543-9. doi: 10.1213/ANE.0000000000000319.

49. Cork RC, Vaughan RW, Humphrey LS. Precision and accuracy of intraoperative temperature monitoring.Anesth Analg. 1983;62:211-4. doi: 10.1213/00000539-198302000-00016.

50. Ash CJ, Cook JR, McMurry TA, Auner CR. The use of rectal temperature to monitor heat stroke. Mo Med. 1992;89:283-8.

51. Robinson JL, Seal RF, Spady DW, Joffres MR. Comparison of esophageal, rectal, axillary, bladder, tympanic, and pulmonary artery temperatures in children. J Pediatr. 1998;133:553-6. doi: 10.1016/S0022-3476(98)700678.

52. Tsuei BJ, Kearney PA. Hypothermia in the trauma patient. Injury. 2004;35:7-15. doi: 10.1016/S00201383(03)00309-7.

53. Sund-Levander M, Grodzinsky E. Time for a change to assess and evaluate body temperature in clinical practice. Int J Nurs Pract. 2009;15:241-9. doi: 10.1111/j.1440-172X.2009.01756.x.

54. Lichtenbelt W. Brown adipose tissue and the regulation of nonshivering thermogenesis. Curr Opin Clin Nutr Metab Care. 2012;15:547-52. doi: 10.1097/MCO.0b013e3283599184.

55. Aslam AF, Aslam AK, Vasavada BC, Khan IA. Hypothermia: evaluation, electrocardiographic manifestations, and management. Am J Med. 2006;119:297-301. doi: 10.1016/j.amjmed.2005.09.062.

56. Goila AJ, Pawar M. The diagnosis of brain death. Indian J Crit Care Med. 2009;13:7-11. doi: 10.4103/09725229.53108.

57. Reuler JB. Hypothermia: pathophysiology, clinical settings, and management. Ann Intern Med.1978;89:519-27. doi: 10.7326/0003-4819-89-4-519.

58. Hess JR, Brohi K, Dutton RP, Hauser CJ, Holcomb JB, Kluger Y, et al. The coagulopathy of trauma: a review of mechanisms. J Trauma. 2008;65:748-54. doi: 10.1097/TA.0b013e3181877a9c.

59. Rohrer MJ, Natale AM. Effect of hypothermia on the coagulation cascade. Crit Care Med.1992;20:1402-5. doi: 10.1097/00003246-199210000-00007.

60. Michelson AD, MacGregor H, Barnard MR, Kestin AS, Rohrer MJ, Valeri CR. Reversible inhibition of human platelet activation by hypothermia in vivo and in vitro. Thromb Haemost. 1994;71:633-40.

61. Brohi K, Cohen MJ, Davenport RA. Acute coagulopathy of trauma: mechanism, identification and effect. Curr Opin Crit Care. 2007;13:680-5. doi: 10.1097/MCC.0b013e3282f1e78f. 
62. MacLeod JBA, Lynn M, McKenney MG, Cohn SM, Murtha M. Early coagulopathy predicts mortality in trauma. J Trauma. 2003;55:39-44. doi: 10.1097/01.TA.0000075338.21177.EF.

63. Bukur M, Hadjibashi AA, Ley EJ, Malinoski D, Singer M, Barmparas G, et al. Impact of prehospital hypothermia on transfusion requirements and outcomes. J Trauma Acute Care Surg. 2012;73:1195-201. doi: 10.1097/TA.0b013e31826fc7d9.

64. Maani CV, DeSocio PA, Holcomb JB. Coagulopathy in trauma patients: what are the main influence factors? Curr Opin Anaesthesiol. 2009;22:255-60. doi: 10.1097/ACO.0b013e32832922be.

65. Martini WZ. The effects of hypothermia on fibrinogen metabolism and coagulation function in swine.Metabolism. 2007;56:214-21. doi: 10.1016/j.metabol.2006.09.015.

66. Frisch, D. E. (1995). Hypothermia in the trauma patient. AACN Clin Issues, 6(2), 196.

67. Peng, Y., \& Bongard, F. S. (1999). Hypothermia in trauma patients. J Am Coll Surg, 188(6), 685. 